\title{
The Role of Interleukin in Ectopic Pregnancy: A Systematic Review
}

\author{
Cahyono Hadi ${ }^{1}$, Jethro Budiman ${ }^{2,3}$ (D) Awal Prasetyo ${ }^{3,4}$, Cipta Pramana, ${ }^{5,6 *(\mathbb{D})}$ \\ ${ }^{1}$ Department of Obstetrics and Gynecology, Faculty of Medicine, Public Health and Nursing, Universitas Gadjah Mada \\ (FK-KMK UGM), Yogyakarta, Indonesia; ${ }^{2}$ Department of Emergency Unit, Panti Wilasa Citarum Hospital, Semarang, Indonesia; \\ ${ }^{3}$ Department of Anatomic Pathology, Faculty of Medicine, Diponegoro University, dr. Kariadi Hospital, Semarang, Indonesia; \\ ${ }^{4}$ Department of Biomedical Science, Faculty of Medicine, Diponegoro University, Semarang, Indonesia; ${ }^{5}$ Department of \\ Obstetrics and Gynecology, K.R.M.T. Wongsonegoro Hospital, Semarang, Indonesia; ${ }^{6}$ Department of Obstetrics and \\ Gynecology, Medical Faculty, Tarumanagara University, Jakarta, Indonesia
}

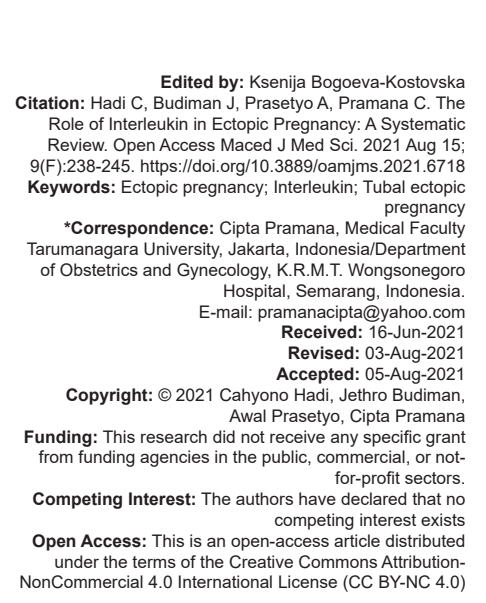

\begin{abstract}
BACKGROUND: Ectopic pregnancy (EP) is the implantation of an embryo outside the eutopic cavity with the most location of EP is in the fallopian tube (FT), known as tubal EP (TEP). The FT of TEP expresses higher levels of proinflammatory cytokines such as interleukin-1 (IL-1), IL-6, and IL-8.

AIM: The study aimed to look systematically into the current literature and carefully analyze the results to explore the role of IL in EP.

METHODS: Three independent reviewers conducted the literature search through some electronic databases searching for articles fulfilling inclusion and exclusion criteria. The lead author independently assessed the risk of bias of each of the 313 articles identified in database searching, 12 articles met the criteria for this review.

CONCLUSION: IL-6 and IL-8 have diagnostic significance in predicting EP with the cutoff levels of IL-6 and IL-8
\end{abstract} which were 26.48 and $40 \mathrm{pg} / \mathrm{mL}$. Further, research is needed for the role of other interleukins in EP.

\section{Introduction}

Ectopic pregnancy (EP) is the implantation of an embryo outside the eutopic cavity with the most location of EP is in the fallopian tube (FT), known as tubal EP (TEP). TEP is one of the most causes of maternal morbidity and mortality in the first trimester [1], [2], [3], [4]. The incidence of TEP is approximately $1-2 \%$ of all pregnancies in the US and Europe. In developing countries, the incident rate of TEP is higher and the mortality rate is about $10 \%$ [1], [5], [6], [7].

Increased levels of pro-inflammatory cytokines, induced by paracrine signaling from the embryo, characterize the endometrium during early implantation and are responsible for the activation of the proteins for embryo receptivity, adhesion, and trophoblast invasion. Interleukin (IL)-11 is obligatory for adequate decidualization and trophoblast invasion [1], [8], [9]. In the FT, pro-inflammatory cytokines caused by tubal damage from infection and/or smoking are believed to cause upregulation of cytokines that promote embryo receptivity, leading to EP. Pelvic inflammatory disease
(PID) is thought to be the main predisposing factor in about $50 \%$ of the patients with EP [1], [8], [10]. Cytokines are known to be pivotal in the communication of the FT and the developing embryo. Serum levels of various inflammatory cytokines and chemokines such as IL-1 $1 \beta$, IL-6, IL-8, interferon (IFN)- $\gamma$, tumor necrosis factor (TNF)- $\alpha$, and granulocytemacrophage colony-stimulating factor are higher in women with EP than in women with normal eutopic pregnancy [1], [2], [8], [11].

The inflammatory responses in the FT induce the activation of immune cells into the local sites [1]. These cells generate persistent tubal tissue damage by increasing the inflammatory responses and guide the embryo to migrate toward the inflammatory site by provoking the production of pro-inflammatory signals, as well as establish an environment conducive to embryo implantation by inducing implantation-associated molecules expression in the tubal epithelium. On the other hand, the inflammation affects tubal motility by reducing cilia beat frequency (CBF) and smooth muscle contraction, leading to embryo retention in FT [1], [12], [13], [14]. 
The FT tissue of TEP expresses higher levels of pro-inflammatory cytokines such as IL-1, IL-6, and IL-8 [1], [2], [8]. IL-1 plays a role in mediating the interaction between the FT and the implanting embryo, which regulates implantation. IL-1 is also reported to be produced by tubal epithelial cells in response to Chlamydia trachomatis infection and causes extensive destruction of the ciliated cells and with TNF- $\alpha$ stimulate IL-8 mRNA (which is a chemoattractant for neutrophils) and IL-6. This effect is reversed by the IL-1 antagonist, which confirms the direct toxic effects of IL-1. IL-8 mediates its effects on binding to two receptors, IL-8RA (CXCR1) and IL-8RB (CXCR2). IL-8 is associated with immune response-mediated tissue damage and chronic inflammatory diseases through the recruitment of leukocytes. IL-6 is a pro-inflammatory and immunoregulatory cytokine and is important for the activation of neutrophils, which mediate oxidative respiratory burst responses and induce the enzymatic degradation of tissue using metalloproteinases, serine proteinases, and their inhibitors. IL- 6 also reduces the CBF of tubal epithelium, while anti-IL- 6 restores the ciliary activity [1], [2], [8], [11].

Pro-inflammatory cytokines expressed by TP may play a role in diagnosing or predicting EP. The role of IL in EP has been reported and explained in various studies, but there was no systematic review of it. The study aimed to look systematically into the current literature and carefully analyze the results to explore the role of IL in EP.

\section{Review of Literature}

This systematic review was conducted by the Cochrane handbook for systematic reviews and is reported using the guideline of preferred reporting items for systematic review and meta-analysis [15], [16]. This systematic review follows five steps of systematic review: Framing questions for a review, identifying relevant work, assessing the quality of studies, summarizing the evidence, and interpreting the findings.

\section{Scope of the review}

Inclusion criteria:

1. Publication type:

- $\quad$ Full-text articles discussing the role of IL in EP

- $\quad$ Primary studies of every design (case study, case series, cross-sectional, case-control, cohort, and clinical trial).

2. Language of publication: English

3. Time of publication: January 2000-December 2020
4. Methodology: Studies included must explain the role of IL in EP.

\section{Exclusion criteria:}

1. Objective and outcome measures are not relevant (are not about the role of IL in EP)

2. Confounding variables are related to outcome in the role of IL in EP (such as had comorbidities or autoimmune disease history).

\section{Literature search}

A systematic search strategy was followed in these electronic databases: Cambridge Core, Clinical Key, EBSCO, Emerald Insight, JSTOR, Medline, Nature, ProQuest, PubMed, Science Direct, Scopus, and Springer Link. The search was conducted using the following keywords for title and abstract: (IL OR IL) AND (EP OR). The reference lists of retrieved papers were also examined to avoid missing any published data.

\section{Data collection and analysis}

Studies were selected for retrieval after two independent reviewers (AP and JB) had collected titles and abstracts identified in electronic searches. The results of the two reviewers were compared by a third independent reviewer $(\mathrm{CH})$, and any differences of opinion were resolved by discussion. Full papers from potential studies were independently assessed by the investigators (AP, JB, and $\mathrm{CP}$ ).

All studies selected for this systematic review were screened by two reviewers independently to validate the results (AP and JB). The data from all retrieved studies were presented in a summary table (Table 5) featuring key points of each study. The following data were collected: First author, country, and year; study design, sample, outcome measure, and result.

\section{Quality assessment}

The lead author independently assessed the quality assessment and risk of bias of each of the included studies and discussed their assessments with the other two authors to achieve consensus. Quality assessment and risk of bias within studies were assessed using criteria developed by Hawker et al. [17], [18]. Ratings were assigned (very poor, poor, fair, good, and not applicable) across nine different categories: Abstract and title; introduction and aim; method and data; sampling; data analysis; ethic and bias; result; generalizability; and implication and usefulness. The risk of bias potentially affecting the cumulative evidence across studies was determined by examining study methods, ethics committee approvals, study funding, and conflicts of interest [17], [18]. Newcastle-Ottawa scale adapted for 
the cross-sectional study was also used to assess crosssectional studies; interpretation of total score was: 9-10 points were considered in very good studies, 7-8 were considered in good studies, 5-6 points were considered in satisfactory studies, and 0-4 were considered in unsatisfactory studies [19], [20]. Newcastle-Ottawa scale for the case-control study was also used to assess case-control study; interpretation of total score was $\geq 7$ points that were included in good studies, 5-6 points were included in fair studies, and $<5$ points were included in poor studies. Newcastle-Ottawa scale for the cohort study was also used to assess prospective study; interpretation of total score was $\geq 7$ points that were included in good studies, 5-6 points were included in fair studies, and $<5$ points were included in poor studies [19], [21], [22], [23].

\section{Results}

\section{Selection of articles for review}

Figure 1 summarizes the identified, screened, and included articles for review. Initially, 305 peerreviewed articles were identified from electronic databases and an additional eight articles were identified through other sources (search engine). After removing duplicates, 177 articles remained for the title and abstract screening. Articles that did not meet the inclusion and exclusion criteria were not further screened. Seventeen articles were screened for eligibility of which 12 articles met all the inclusion criteria.

\section{Assessment of study validity (quality assessment and risk of bias)}

All eligible studies were associated with the role of IL in EP. Table 1 provided quality assessment and risk of bias by Hawker et al. and all of the components are fair and good. Table 2 provided quality scores for crosssectional study and all of the studies got $6-7$ points that were considered satisfactory and good studies. Table 3 provided quality scores for the case-control study and all of the studies got 6-8 points that were considered in good and fair studies. Table 4 provided quality scores for cohort study and all of the studies got 7 points that were considered in good studies.

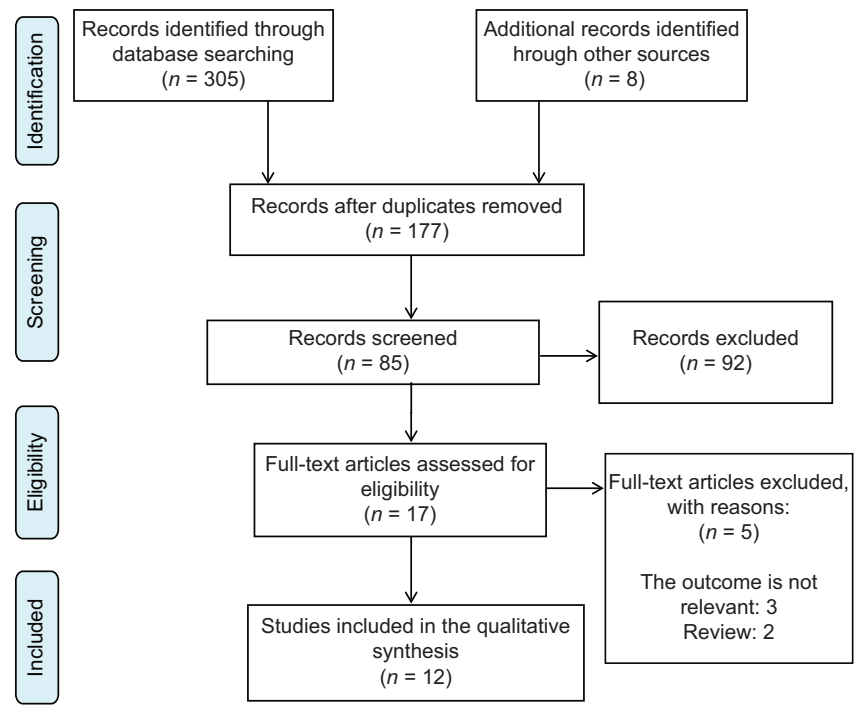

Figure 1: Preferred reporting items for systematic reviews and metaanalysis [16]

\section{Study characteristic}

Study characteristics for the included studies are shown in Table 5. The majority of the studies (7 of 12) were case-control studies. The studies reported the role of $\mathrm{IL}-1, \mathrm{IL}-2, \mathrm{IL}-4, \mathrm{IL}-6, \mathrm{IL}-7, \mathrm{IL}-8$, IL-10, IL-11, IL-15, IL-17, and IL-22 in EP.

\section{Discussion}

\section{The role of IL in EP}

ILs are a group of cytokines with immunomodulatory function and regulate inflammatory responses in the human body and these cytokines also play a part in human conception. T-helper type 1 (Th1) cells produce various cytokines (such as IL-2, IFN, and TNF- $\alpha$ ) that are involved in cell-mediated rejection processes while T-helper type 2 (Th2) cells mainly produce IL-4, IL-6, and IL-10; which inhibit cellmediated immunity and enhance humoral immune responses, thereby promoting implantation [34]. IL-1,

Table 1: Quality assessment and risk of bias by Hawker et al. [18]

\begin{tabular}{|c|c|c|c|c|c|c|c|c|c|c|}
\hline S. No. & First author, year & Abstract and title & Introduction and aim & Method and data & Sampling & Data analysis & Ethic and bias & Finding & Generalisability & $\begin{array}{l}\text { Implication and } \\
\text { usefulness }\end{array}$ \\
\hline 1. & Ashshi, 2016 [24] & Fair & Good & Good & Good & Good & Good & Good & Good & Good \\
\hline 2. & Balasubramaniam, 2012 [8] & Good & Good & Good & Good & Fair & Good & Good & Good & Good \\
\hline 3. & Daponte et al., 2013 [25] & Good & Good & Good & Good & Fair & Good & Good & Good & Good \\
\hline 4. & lyibozkurt et al., 2010 [26] & Good & Fair & Fair & Fair & Good & Good & Good & Good & Good \\
\hline 5. & Huang et al., 2005 [27] & Good & Good & Good & Good & Fair & Good & Good & Good & Good \\
\hline 6. & Lekovich et al., 2015 [28] & Good & Good & Good & Fair & Good & Good & Good & Good & Good \\
\hline 7. & Lombardelli et al., 2016 [29] & Good & Good & Good & Fair & Good & Good & Good & Good & Good \\
\hline 8. & Ma et al., 2020 [30] & Good & Good & Fair & Fair & Good & Fair & Good & Good & Good \\
\hline 9. & Rajendiran et al., 2016 [31] & Good & Good & Good & Fair & Good & Fair & Good & Good & Good \\
\hline 10. & Rango et al., 2004 [32] & Fair & Good & Fair & Fair & Good & Good & Good & Good & Good \\
\hline 11. & Shao et al., 2016 [33] & Good & Fair & Fair & Fair & Good & Good & Good & Good & Good \\
\hline 12. & Soriano et al., 2003 [34] & Good & Good & Good & Fair & Good & Good & Good & Good & Good \\
\hline
\end{tabular}


secreted by cytotrophoblasts during first-trimester pregnancy, has a role in trophoblast invasion and tissue repair. IL-6, produced by decidual cell populations, and is a potent pro-angiogenic cytokine that stimulates the proliferation of endothelial cells in vitro, majorregulators ofendometrialreceptivityandblastocystimplantation, and regulates the behavior of the female reproductive tract and gestational tissues. IL-8 is involved in the normal implantation process and is upregulated in the endometrium during decidualization and early pregnancy. IL-10, generated by cytotrophoblasts and decidual $\mathrm{T}$ cells, protect the fetal-placental interface by reducing the cytokine secretions of Th1 cells and macrophages [8], [24], [35].

Table 2: Newcastle-Ottawa scale adapted for cross-sectional study [20]

\begin{tabular}{|c|c|c|c|c|c|c|c|c|}
\hline \multirow[t]{2}{*}{ S. No. } & \multirow[t]{2}{*}{ First author, country } & \multicolumn{3}{|c|}{ Selection } & \multirow[t]{2}{*}{ Comparability } & \multicolumn{2}{|c|}{ Outcome } & \multirow[t]{2}{*}{ Total } \\
\hline & & 1 & 23 & 4 & & 1 & 2 & \\
\hline 1. & Lombardelli et al., 2016 [29] & * & * & ** & * & * & * & 7 \\
\hline 2. & Shao et al., 2016 [33] & * & * & $\star *$ & & * & * & 6 \\
\hline
\end{tabular}

The role of IL-1 was explained in three studies [27], [28], [33]. More specifically related to mechanisms of implantation, the IL-1 system may be one of the major candidates for these molecular regulators in local intercellular interactions during embryonic implantation. The IL-1 system is a family of polypeptides composed of two agonists, IL-1 $\alpha$ and IL-1 $\beta$, and an inhibitor, IL-1 receptor antagonist (IL-1ra), as well as two receptors (type 1 and type 2).

Table 3: Newcastle-Ottawa scale (case-control study)

\begin{tabular}{|c|c|c|c|c|c|c|c|c|c|c|}
\hline \multirow[t]{2}{*}{ S. No. } & \multirow[t]{2}{*}{ First author, year } & \multicolumn{4}{|c|}{ Selection } & \multirow[t]{2}{*}{ Comparability } & \multicolumn{3}{|c|}{ Exposure } & \multirow[t]{2}{*}{ Total } \\
\hline & & 1 & 2 & 3 & 4 & & 1 & 2 & 3 & \\
\hline 1. & Ashshi, 2016 [24] & * & * & * & * & & & * & * & 7 \\
\hline 2. & Balasubramaniam, 2012 [8] & * & * & * & * & & * & * & * & 7 \\
\hline 3. & Daponte et al., 2013 [25] & * & * & * & * & & * & * & * & 7 \\
\hline 4. & lyibozkurt et al., 2010 [26] & * & & * & * & & * & * & * & 6 \\
\hline 5. & Huang et al., 2005 [27] & * & * & * & * & & * & * & * & 7 \\
\hline 6. & Ma et al., 2020 [30] & * & * & * & * & * & * & * & * & 8 \\
\hline 7. & Rajendiran et al., 2016 [31] & * & & * & * & * & * & * & * & 7 \\
\hline
\end{tabular}

Both IL-1 agonist and receptor antagonists are recognized by $\mathrm{IL}-1$ receptor type 1 and trigger signal responses in target cells. IL-1ra is a specific inhibitor to IL-1 agonist, which competes with IL-1 for the binding site of IL-1 receptor type 1 and blocks signal transduction. IL-1 is also expressed in human endometrium and has been shown to play an integral role in local cellular interactions during implantation [28], [36], [37]. According to Huang et al., an earlier upregulation of IL-1 receptor type 1 and downregulation IL-1 expression in human FTs was observed in TEP [27]. This suggests that the sequential cytokines expression maternally

Table 4: Newcastle-Ottawa scale (cohort study)

\begin{tabular}{|c|c|c|c|c|c|c|c|c|c|}
\hline \multirow[t]{2}{*}{ S. No. } & \multirow[t]{2}{*}{ First author, year } & \multicolumn{3}{|c|}{ Selection } & \multirow[t]{2}{*}{ Comparability } & \multicolumn{3}{|c|}{ Outcome } & \multirow[t]{2}{*}{ Total } \\
\hline & & 1 & 2 & 3 & & 1 & 2 & 3 & \\
\hline 1. & Lekovich et al., 2015 [28] & * & * & * & * & * & * & * & 7 \\
\hline 2. & Soriano et al., 2003 [34] & * & * & * & * & * & * & * & 7 \\
\hline
\end{tabular}

direct human embryonic implantation independent of the location, either tubal or uterine, of the embryo. In addition, the ratio of IL-1 to IL-1ra in human endometrial stromal cells was statistically significantly increased in the presence of IL-1. It is interesting that, in the present study, a lower ratio of IL-1 agonist to IL-1ra was demonstrated in human FT with EP compared with normal controls, suggesting an inappropriate ratio of IL-1 agonist to antagonist may play a role in EP. IL-1 expression may play a crucial role in embryo-maternal interaction during the process of early embryonic implantation as embryos transverse the tube. This expression and an inappropriate ratio of agonist and receptor antagonist in FT may probably indicate an earlier dialogue between the early developing embryo and FT epithelium, predisposing the embryo to earlier implantation in the FT [27], [28].

IL-6 level had been reported to be significantly increased in EP in two studies, reported to have a diagnostic value for EP in two studies, and IL-6 genes expression level was increased in EP in one study [8], [24], [30], [31], [34]. The cutoff level of IL-6 level was $26.48 \mathrm{pg} / \mathrm{ml}$ with moderate accuracy (with a sensitivity of $53.57 \%$ and specificity of $80 \%$ ).IL-6 level was also increased in women with intrauterine abortion, but the increasing level of IL-6 in EP was significantly higher than in intrauterine abortion patients [31]. Balasubramaniam et al. reported about the expression of IL-6 was significantly increased near the implantation site in FT with EP as compared with normal. In addition, there were significant differences in the level of expression of IL-6 and IL-8 in TEP near and away from the implantation site. This reflected that implantation affects the expression of IL-6 and IL-8 in the tubal epithelium locally and not throughout the FT. Balasubramaniam et al. were also demonstrated that IL-6, IL-8, and CXCR1 were upregulated in the epithelium of FTs with gestation and particularly near the implantation site, while IL-6Ra and CXCR2 are downregulated from the implantation site [8].

IL-8 level had been reported to be significantly increased in EP in two studies, reported to have a diagnostic value for EP in one study, and IL-8 genes expression level was increased in EP in one study [8], [30], [33], [34]. The cutoff level of IL-8 level was $>40 \mathrm{pg} / \mathrm{mL}$ with a sensitivity of $82.4 \%$, a specificity of $81.8 \%$, and positive and negative predictive values (NPV) of $58.3 \%$ and $93.8 \%$ in combination, IL-8 and IL-6 cut points of $40 \mathrm{pg} / \mathrm{mL}$ and $16 \mathrm{pg} / \mathrm{mL}$, predicted EP with a sensitivity of $70.6 \%$, a specificity of $94.5 \%$, a positive predictive value (PPV) of $80.0 \%$, and a NPV of $91.2 \%$ [34]. Women with EP and free fluid in the pouch of Douglas had higher serum IL-8 levels than did other women with EP and this condition is related to cytokine hypersecretion by peritoneal macrophages involved in the local inflammatory process. Even after the exclusion of women with fluid in the pouch of Douglas, the EP group had higher serum IL-8 levels 
Table 5: Study characteristic

\begin{tabular}{llll}
\hline S. No. & First author, country, year & Study design & Sample $(\mathrm{n})$ \\
\hline 1. & Ashshi, Indian, 2016 [24] & Case-control & EP: $96(22$ positive CMV) \\
& & & Non-EP: 61 (5 positive CMV)
\end{tabular}

Outcome measure Result

Outcome measure

The role of IL-6 and its

Result

signaling molecules in $\mathrm{CMV}$

- CMV-positive EP group showed the highest significan

increase of the studied molecules by all techniques

infection in EP

- The expression in the non-infected EP group was significantly higher for IL-6 (p:0.004), IL-6Ra (p: 0.007), gp130 (p:0.006),

2. Balasubramaniam, UK, Case-control EP: 50 2012 [8] Non-EP: 25

The expression of IL-8,

CXCR1, CXCR2, IL-6, and and STAT3 ( $p: 0.007)$ compared with control group

IL-6Ra in EP

3. Daponte et al., Greece, Case-control EP: 30 $2013^{25}$ MA: 30

Diagnostic significance of $\mathrm{IL}-15$ and anti-C1q Ab in EP

- The expression levels of IL-6, IL-8, and CXCR1 wer significantly upregulated in the EP group $(p<0.05)$

- The expression levels of CXCR2 and IL-6Ra were not changed in comparison with the normal group $(p>0.05)$

- EP group had elevated significant IL-15 levels compared to other groups with a cutoff of $16 \mathrm{pg} / \mathrm{mL}$ and a negative predictive value of $99 \%$ with a sensitivity for diagnosing an EP of $92 \%(p<0.05)$

- EP group had a lower level of anti-C1q Ab level but not statistically significant $(p>0.05)$

4. lyibozkurt et al., Turkey, Case-control EP: 17 2010 [26] IUP: 19

The role of LIF, IL-10, and

- LIF levels increased significantly in the EP group ( $p: 0.002$ ). Ranges of LIF were $15-300$ and $70-1200 \mathrm{ng} / \mathrm{ml}$ for the IUP and EP groups

- There were no significant differences between IL-10 and IL-11 between groups $(p>0.005)$

5. Huang et al., Taiwan, Case-control EP: 5 2005 [27] Non-EP: 4

IL-1 system mRNA in EP

- IL-1 mRNA expression was decreased, and IL-1RA and IL-1 receptor type 1 were increased in the EP group

- IL-1 receptor type 1 mRNA was statistically significantly increased in paraectopic tubes $(p<0.05)$

- There was a lower ratio of IL-1 to IL-1RA at mRNA in EP

6. Lekovich et al., USA, 2015 [28] Retrospective 307 with the following IVF outcomes: The role of IL-1b and IL-1bLive births: 103 to-IL-1RA ratio in EP (vs. Negative pregnancy tests: 80 Biochemical pregnancies: 52 cycle outcome)

- The mean IL-1b levels were higher in the EP group at cycle days 24 and $28(127.1 \mathrm{pg} / \mathrm{mL}$ and $166.9 \mathrm{pg} / \mathrm{mL}$, respectively) than other IVF outcome groups (15.8-55.3 pg/mL and $14.8-75.5 \mathrm{pg} / \mathrm{mL}$, respectively)

- The IL-1b-to-IL-1RA ratio was 0.18 in the EP group versus EP: 47

7. Lombardelli et al., Italy, Cross-sectionat EP: 6 Miscarriages: 25

The role of IL-4, IL-17, and IL-22 in EP

$0.01-0.09$ in the other groups at cycle day 24

There was a statistically increase of IL-4, IL-17, and IL-22 levels at the implantation site than the levels of these cytokines distant from the implantation site $(p<0.05)$

The role of cytokine genes - TNF- $\alpha$, IL-6, and IL-8 expression levels significantly increased in EP

Ma et al., China, $\quad$ Case-control TEP: 120
2020 [30]
Non-TEP: 30

9. Rajendiran et al., India, Case-control TEP: 28 Miscarriage: 31 2016 [31] IUP: 29

Diagnostic significance of IL-6 and IL-8 in TEP

in the TEP group $(p<0.05)$

- IL-6 level increased significantly in the TEP group compared to other groups with the cutoff of $26.48 \mathrm{pg} / \mathrm{ml}$ with moderate accuracy $(p<0.05)$

- IL-8 level decreased significantly in the TEP group and miscarriage group when compared with the normal pregnancy group $(p<0.05)$

The role of IL-11 in EP Rango et al., Germany, Descriptive Non-EP: 8

Shao et al., China, Cross-sectional TEP: 36 2016 [33] IUP: 50

The role of inflammatory cytokines in Chlamydia Non-pregnant: 139 trachomatis infection in TEP

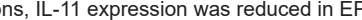
abortion in comparison to other groups

- The rates of Chlamydia trachomatis infection in TEP, IUP, and non-pregnant were $86.11 \%, 60.00 \%$, and $55.40 \%$

- An increase in IL-8 level could differentiate tubal EP (concomitant with Chlamydia trachomatis infection) from IUP and non-pregnant conditions regardless of Chlamydia trachomatis infection (based on ROC)

- An increase in IL-1 $1 \beta$ level and a decrease in IL-10 level were observed in the TEP group with positive Chlamydia trachomatis infection compared to other groups with Chlamydia trachomatis infection

- There were no significant differences in IL-4, IL-6, IL-7, IL-8, TNF- $\alpha$, or IFN-y levels among Chlamydia trachomatis-positive or -negative women under pregnant and non-pregnant conditions $(p>0.05)$

Diagnostic significance of IL-2R, IL-6, IL-8, and TNF- $\alpha$

- II-6 level, IL-8 level, and TNF-a level were statistically higher in EP group compared to other groups $(p<0.05)$ with a cutoff level of IL- $8>40 \mathrm{pg} / \mathrm{mL}$ with a sensitivity of $82.4 \%$, a specificity of $81.8 \%$, and positive and negative predictive values of $58.3 \%$ and $93.8 \%$

Miscarriages: 22 in $E P$

- In combination, IL-8 and IL-6 cut points of $40 \mathrm{pg} / \mathrm{mL}$ and $16 \mathrm{pg} / \mathrm{mL}$, predicted EP with a sensitivity of $70.6 \%$, a specificity of $94.5 \%$, a PPV of $80.0 \%$, and an NPV of $91.2 \%$ - The combination of IL-8, IL-6, and TNF- $\alpha$ cut points of $40 \mathrm{pg} / \mathrm{mL}, 16 \mathrm{pg} / \mathrm{mL}$, and $60 \mathrm{pg} / \mathrm{mL}$, predicted EP with a sensitivity of $52.9 \%$, a specificity of $100 \%$, a PPV of $100 \%$, and an NPV of $87.3 \%$

- There was no statistically significant difference in IL-2R level $(p>0.05)$

Ab: Antibody, C.: Chlamydia, CXCR: C-X-C chemokine receptor, EP: Ectopic pregnancy, gp: Glycoprotein, IFN: Interferon, IL: Interleukin, IUP: Intrauterine pregnancy, LIF: Leukemia inhibitory factor, MA: Missed abortion, NPV: Negative predictive value, PPV: Positive predictive value, R: Receptor, RA: Receptor antagonist, ROC: Receiving operating characteristic, STAT: Signal transducer and activator of transcription, TEP: Tubal ectopic pregnancy, TNF: Tumor necrosis factor.

than did those in the normal pregnancy and miscarriage groups [34]. The upregulation of IL-8 in TEP may create a receptive endometrial-like environment that encourages embryo implantation [8]. Rajendiran et al. reported about IL-8 level was decreased significantly in EP [31]. The probable explanation for this could be that IL-6 also has an anti-inflammatory effect in the early phase of inflammation by decreasing the level of other pro-inflammatory cytokines like IL-8, Thus, in early inflammation, it can be expected that the levels of IL-6 be high but IL-8 to below. The decrease in IL-8 levels could also be due to differential expression of IL-8 due to tubal and peritoneal inflammation. Therefore, this underlying inflammation due to PID could have 
further suppressed the IL-8 levels [31]. The difference in demography variance and sample size is likely contributed to the difference in the result.

EP group had elevated significant IL-15 levels compared to other groups with a cutoff of $16 \mathrm{pg} / \mathrm{mL}$ and a NPV of $99 \%$ with a sensitivity for diagnosing an EP of $92 \%$. IL-15 expression is upregulated in placental tissue of disturbed human first-trimester pregnancy and trophoblast cells were detected as the main source for IL-15 in women with recurrent miscarriages. The trophoblast invasion in EP is different from normal pregnancies and this may explain differences related to IL-15 tissue expression and circulating levels of this cytokine. Trophoblast infiltrating the tube or the peripheral NK cells can be the source of the increased levels of IL-15 in EPs compared to IUPs, but this needs to be explored further. This is by the finding of increased IL-15 levels in EP which due to its protective effect and angiogenic role might explain the survival of trophoblasts while penetrating the tubal wall [25]. There was also a statistically increase of immunoregulatory cytokine levels of IL-4, IL-17, and IL-22 at the implantation site than the levels of these cytokines distant from the implantation site $(p<0.05)$ [29]. IL-4, IL-17, and IL-22 are known to increase in pregnancy [29], [35]. IL-17 also accumulates in both the decidua and the peripheral blood in patients with recurrent pregnancy loss [35].

A decrease in IL-10 level was observed in the TEP group with positive $C$. trachomatis infection compared to other groups with C. trachomatis infection [33]. In tubal abortions, IL-11 expression was reduced in EP abortion in comparison to other groups. IL-10 and IL-11 were known to increase the occurrence of implantation and pregnancy [32]. There was no statistically significant difference in IL-2R level $(p>0.05)$ [34]. There were no significant differences in IL-4, IL-6, IL-7, and IL-8 levels among C. trachomatispositive or -negative women under pregnant and non-pregnant conditions ( $p>0.05$ ) [33]. There were no significant differences of IL-10 and IL-11 between groups of EP and normal pregnancy [26].The difference of demography variance and minimum sample number may be contributed in this insignificant and the difference in this result.

\section{Strength and limitation of the study}

The present systematic review involved studies that reported 12 studies related to the role of IL in EP. Most of the studies were case-control studies (7 of 12) and reported about ten ILs.

The limitation of the study was the variance of the demography, confounding variable in each study (there were confounding variables that cannot be controlled in human subjects like the severity of the disease and care-seeking behavior), and also the limitation of study type (there was no experimental study and majority of the studies were retrospective studies).

\section{Future implication}

The current systematic review is expected to be a scientific reading, material, and consideration to clinicians related to the role of IL in EP. Further research is needed for the cutoff value and genetic study (and genetic variance) in each of $\mathrm{IL}$ and optimization of the IL in early detection of EP so can minimize the complication of EP.

\section{Conclusion}

IL-6 and IL-8 have diagnostic significance in predicting EP with the cutoff levels of IL-6 and IL-8 which were 26.48 and $40 \mathrm{pg} / \mathrm{mL}$. Further research is needed for the role of other ILs in EP.

\section{References}

1. Wang $X$, Lee CL, Li RH, Vijayan M, Duan YG, Yeung WS et al. Alteration of the immune cell profiles in the pathophysiology of tubal ectopic pregnancy. Am J Reprod Immunol. 2019;81(4):e13093. https://doi.org/10.1111/aji.13093

PMid:30672642

2. Rajendiren S, Dhiman P. Biomarkers of Ectopic Pregnancy Present and Future. London: IntechOpen; 2015. p. 48-75. https://doi.org/10.5772/58954

3. Gencdal S, Aydogmus H, Gencdal NK, Destegul E, Ekmekci E. Evaluation of the neutrophil-lymphocyte ratio and plateletlymphocyte ratio in patients with ectopic pregnancies.J Clin Gynecol Obstet. 2019;8(3):81-4. https://doi.org/10.14740/ jcgo559

4. Tok A, Özer A, Baylan FA, Kurutaş EB. Copper/zinc ratio can be a marker to diagnose ectopic pregnancy and is associated with the oxidative stress status of ectopic pregnancy cases. Biol Trace Elem Res. 2021;199(6):2096-103. https://doi. org/10.1007/s12011-020-02327-0 PMid:32803526

5. Ghafouri-Fard, S, Shoorei, H, Taheri, M. The role of microRNAs in ectopic pregnancy:A concise review. Non-coding RNA Res. 2020;5(2):67-70. https://doi.org/10.1016/j.ncrna.2020.04.002 PMid:32346661

6. Kan Ö, Gemici A, Alkilic A, Cetindag EN, Cakir C, Dur R, et al. The effect of preoperative neutrophil-to-lymphocyte ratio and platelet-to-lymphocyte ratio on predicting rupture risk in tubal ectopic pregnancies. Gynecol Obstet Invest. 2019;84(4): 378-82. https://doi.org/10.1159/000496543 PMid:30654361

7. Iqbal A, Saeed M, Amjad S.A cross-sectional research: Incidence of tubal ectopic pregnancy versus prolidase activity and oxidative stress: One year research experience at service hospital, Lahore. Indo Am J Pharm Sci. 2018;5(5):4533-7.

8. Balasubramaniam ES, Van Noorden S, El-Bahrawy M. 
The expression of interleukin (IL)-6, IL-8, and their receptors in fallopian tubes with ectopic tubal gestation. Fertil Steril. 2012;98(4):898-904. https://doi.org/10.1016/j. fertnstert.2012.06.004

\section{PMid:22763101}

9. Dimitriadis E, White CA, Jones RL, Salamonsen LA. Cytokines, chemokines and growth factors in endometrium related to implantation. Hum Reprod Updat. 2005;11(6):613-30. https:// doi.org/10.1093/humupd/dmi023

PMid:16006437

10. Shaw JL, Dey SK, Critchley HO, Horne AW. Current knowledge of the aetiology of human tubal ectopic pregnancy. Hum Reprod Updat. 2010;16(4):432-44. https://doi.org/10.1093/humupd/ dmp057

\section{PMid:20071358}

11. Cartwright J, Duncan WC, Critchley HO, Horne AW. Serum biomarkers of tubal ectopic pregnancy: Current candidates and future possibilities. Reproduction. 2009;138(1):9-22. https://doi. org/10.1530/rep-09-0060

PMid:19321656

12. $\mathrm{Xu} \mathrm{J,} \mathrm{Luo} X, \mathrm{Qu} \mathrm{S}$, Yang G, Shen N.B cell activation factor (BAFF) induces inflammation in the human fallopian tube leading to tubal pregnancy. BMC Pregnancy Childbirth. 2019;19(1):169. https://doi.org/10.1186/s12884-019-2324-5

PMid:31088412

13. Donmez EE. Importance of inflammatory markers in predicting the rupture in ectopic pregnancies. Eur $\mathrm{J}$ Med Oncol. 2018;2(4):198-202. https://doi.org/10.5336/jcog.2017-59571

14. Sucu S, Bademkiran MH, Özcan HÇ, Kömürcü ÖZ, Bayramoglu D, Balat ÖZ. Oxidative stress markers in tubal ectopic pregnancy. Turk Klin Jinekol Obstet. 2018;28(1):9-13.

15. Higgins J, Green S. Cochrane handbook for Systematic Reviews of Intervention 5.2. United Kingdom: John Wiley and Sons; 2017. p. 1-50.

16. Moher D, Liberati A, Tetzlaff J, Altman DG, Group TP. Preferred reporting items for systematic reviews and meta-analyses: The PRISMA statement. PLoS Med. 2009;6(7):e1000097. https:// doi.org/10.1371/journal.pmed.1000097

PMid:19621072

17. Clay-Williams R, Ludlow K, Testa L, Li Z, Braithwaite J. Medical leadership, a systematic narrative review: Do hospitals and healthcare organisations perform better when led by doctors? BMJ Open. 2017;7(9):e014474. https://doi.org/10.1136/ bmjopen-2016-014474

PMid:28947438

18. Hawker S, Payne S, Kerr C, Hardey M, Powell J. Appraising the evidence: Reviewing disparate data systematically. Qual Heal Res. 2002;12(9):1284-99. https://doi. org/10.1177/1049732302238251

\section{PMid:12448672}

19. Wells G, Shea B, O'Connell D, Peterson J, Welch V, Losos M, et al. The Newcastle-Ottawa Scale (NOS) for Assessing the Quality of Nonrandomised Studies in Meta-Analyses; 2019.

20. Herzog R, Álvarez-Pasquin MJ, Díaz C, Luis J, Barrio D, Estrada JM, et al. Are healthcare workers' intentions to vaccinate related to their knowledge, beliefs and attitudes? A systematic review. BMC Public Health. 2013;13:154. https://doi. org/10.1186/1471-2458-13-154

21. Viswanathan M, Ansari MT, Berkman ND, Chang S, Hartling L, McPheeters M, et al. Methods Guide for Effectiveness and Comparative Effectiveness Reviews, Assessing the Risk of Bias of Individual Studies in Systematic Reviews of Health Care Interventions. USA: AHRQ Publication; 2008. https://doi. org/10.23970/ahrqepcmethguide2

22. Islam $M$, Iqbal $U$, Walther $B$, Atique $S$, Dubey $N$, Nguyen $P$ et al. Benzodiazepine use and risk of dementia in the elderly population:A systematic review and meta-analysis. Neuroepidemiology. 2016;47(3-4):181-91. https://doi. org/10.1159/000454881

PMid:28013304

23. Luchini C, Stubbs B, Solmi M, Veronese N. Assessing the quality of studies in meta-analyses: Advantages and limitations of the newcastle ottawa scale. World J Metaanal. 2017;5(4): 80-4. https://doi.org/10.13105/wjma.v5.i4.80

24. Ashshi AM. Aberrant expression of interleukin- 6 and its receptor in Fallopian tubes bearing an ectopic pregnancy with and without tubal cytomegalovirus infection. Virusdisease. 2016;27(4): 340-50. https://doi.org/10.1007/s13337-016-0342-8 PMid:28004013

25. Daponte A, Deligeoroglou E, Garas A, Pournaras S, Hadjichristodoulou C, Messinis IE. Activin a and follistatin as biomarkers for ectopic pregnancy and missed abortion. Dis Markers. 2013;35(5):497-503. https://doi. org/10.1155/2013/969473

PMid:24222717

26. lyibozkurt AC, Kalelioǧlu I, Gursoy S, Corbacioglu A Gurelpolat N, Karahan GE, et al. Evaluation of serum levels of interleukin-10, interleukin-11 and leukemia inhibitory factor in differentiation of eutopic and tubal ectopic pregnancies. Clin Exp Obstet Gynecol. 2010;37(3):217-20.

PMid:21077528

27. Huang HY, Chan $\mathrm{SH}, \mathrm{Wu} \mathrm{CH}$, Wang $\mathrm{CW}$, Lai CH, Soong YK. Interleukin-1 system messenger ribonucleic acid and protein expression in human fallopian tube may be associated with ectopic pregnancy. Fertil Steril. 2005;84(5):1484-92. https://doi. org/10.1016/j.fertnstert.2005.05.039

PMid:16275248

28. Lekovich J, Witkin SS, Doulaveris G, Orfanelli T, Shulman B, Pereira $N$, et al. Elevated serum interleukin-1 $\beta$ levels and interleukin-1 $\beta$-to-interleukin-1 receptor antagonist ratio 1 week after embryo transfer are associated with ectopic pregnancy. Fertil Steril. 2015;104(5):1190-4. https://doi.org/10.1016/j. fertnstert.2015.07.1145

PMid:26279136

29. Lombardelli L, Logiodice F, Aguerre-Girr M, Kullolli O, Haller H, Casart $\mathrm{Y}$, et al. Interleukin-17-producing decidual CD4+ T cells are not deleterious for human pregnancy when they also produce interleukin-4. Clin Mol Allergy. 2016;14(1):1-14. https:// doi.org/10.1186/s12948-016-0039-y

30. Ma L, Li Z, Xi S, Guo Q, Zhao P, Li W, et al. Tubal ectopic pregnancy occurrence is associated with high expressions of prokineticin receptors and aberrant secretion of inflammatory cytokines. Am J Transl Res. 2020;12(9):5741-51

PMid:33042453

31. Rajendiran S, Kumar GP, Nimesh A, Dhiman P, Shivaraman K, Soundararaghavan S. Diagnostic significance of IL-6 and IL-8 in tubal ectopic pregnancy.J Obs Gynaecol. 2016;36(7):909-11. https://doi.org/10.1080/01443615.2016.1174821 PMid:27612507

32. Rango UV, Alfer J, Kertschanska S, Kemp B, Müller-Newen G, Heinrich PC, et al. Interleukin-11 expression: Its significance in eutopic and ectopic human implantation. Mol Hum Reprod. 2004;10(11):783-92. https://doi.org/10.1093/molehr/gah107 PMid:15465850

33. Shao R, Feng Y, Zou S, Li X, Cui P, Billig H. Quantitative analysis of hormones and inflammatory cytokines in Chlamydia trachomatis-infected women with tubal ectopic pregnancy and early intrauterine pregnancy. Data Brief. 2016;6:135-42. https:// doi.org/10.1016/j.dib.2015.11.048

PMid:26858978 
34. Soriano D, Hugol D, Quang NT, Darai E. Serum concentrations of interleukin-2R (IL-2R), IL-6, IL-8, and tumor necrosis factor alpha in patients with ectopic pregnancy. Fertil Steril. 2003;79(4): 975-80. https://doi.org/10.1016/s0015-0282(02)04853-7

PMid:12749440

35. Zhang M, Xu J, Bao X, Niu W, Wang L, Du L, et al. Association between genetic polymorphisms in interleukin genes and recurrent pregnancy loss a systematic review and meta-analysis. PLoS One. 2017;12(1):e0169891. https://doi.org/10.1371/ journal.pone.0169891

PMid:28103273

36. Kaneko, Naoe Jurata M, Yamamoto T, Morikawa S, Masumoto J. The role of interleukin-1 in general pathology. Inflamm Regeb. 2019;39(12):1-16.

PMid:31182982

37. Abbas A, Lichtman A, Pillai S. Cellular and Molecular Immunology. $9^{\text {th }}$ ed. Amsterdam: Elsevier; 2017. 